\title{
NOXA BH3 Priming
}

National Cancer Institute

\section{Source}

National Cancer Institute. NOXA BH3 Priming. NCI Thesaurus. Code C134502.

An assay that indirectly quantitates the expression of the antiapoptotic protein, induced myeloid leukemia cell differentiation protein Mcl-1 (MCL1; EAT), in a biological sample. Mitochondria or whole cells are isolated from a patient sample and stained with JC-1. In healthy cells with high mitochondrial membrane potential, JC-1 forms aggregates that emit red fluorescence, while in apoptotic cells with low mitochondrial membrane potential, JC-1 remains a monomer, which emits green fluorescence. The isolate is then exposed to a peptide comprised of the $\mathrm{BH} 3$ domain of phorbol-12-myristate-13acetate-induced protein 1 (PMAIP1; NOXA), which specifically binds to and inhibits the antiapoptotic activity of MCL1. Then the mitochondrial outer membrane permeability (MOMP) is assessed by determining the ratio of red and green JC-1 fluorescence. 